gas when it falls, his death or survival is a question of how few seconds it takes to put on the mask. The cloud of gas is very deadly for some hundreds of yards down a street in the direction of the wind, the length of the most dangerous zone being greatest in narrow streets. Further, everyone should have a clearly thought-out plan in their minds what they are going to do should they encounter gas; this will have to be varied according to circumstances. For example, if they are splashed with a few drops of liquid blister gas the time available to prevent a bad burn is short-a matter of five minutes. A clear plan to enter the first house, drop clothing on the doorstep and wash vigorously with soap and warm water, will prevent them becoming a casualty.

The respirator as a filter of poisoned air depends on the outstanding property of suitably activated charcoal to absorb organic vapours: the charcoal is supplemented by a pad able to hold back the finest particles of dispersed substances. The respirator is the result of prolonged study by experts, aided by the leading men of science. It is an all-purposes defensive weapon as nearly perfect as anything which is mass-produced in such enormous numbers can be. It is carefully tested in the course of manufacture, and is considered to give full protection against any war gases in the concentrations in which they are likely to be encountered by a civilian. It is not exhausted by a single encounter with gas, but should continue effective for many months. It may well be that when a respirator is put on in gas, and however quickly, it will enclose a little of the gas, which will cause irritation during the first minute or so. The impulse to tear off the mask must be resisted; also the thought that the mask is not fitting or the filter is letting gas pass. Previous practice will have proved this thought to be wrong, and very soon the respirator will be comfortable. We can do nothing when a high explosive bomb falls near; we can save our homes if we are quick when incendiary bombs fall on them; we can defeat a gas attack if we have trained ourselves in doing it.

\section{Preparation of Fine Chemicals}

The Advisory Research Council of the Chemical Society, in collaboration with the Association of British Chemical Manufacturers, is putting into operation a scheme for organizing the preparation of fine chemicals in Great Britain by part-time volunteer workers in the laboratories of universities, technical colleges, and other institutions. It is essential to the scheme that compounds so prepared must be required for work of national importance and be not available commercially, and that the manufacturers of fine chemicals are themselves unable, or do not find it convenient, to meet the demands. It is intended that preparations should be carried out on a costprice basis which would include charges for materials, gas, electricity, etc., but not for the workers' services. No profits of any kind will be permitted. Those who wish their names to be added to the list of volunteer helpers in connexion with this scheme should communicate with the General Secretary, Chemical
Society, Piccadilly, London, W.1, to whom inquiries for fine chemicals falling within the scope of the scheme may also be made.

\section{Issues and Parties in India}

AN English resident in the Punjab writes taking exception to views expressed in these columns in a reference to Mr. L. S. Amery's review of the political situation in India in August last (see NATURE, 146. $255 ; 1940)$. He points out that while it is true that there are differences among the Indians themselves, all parties are at one in desiring Home Rule. To attain Home Rule is, or is supposed to be, the purpose of the Indian National Congress; and the preponderancy of the Hindu community in it merely reflects the fact that Hindus are a large majority in the country. It is stated that Moslems are by no means all anti-Nationalist or anti-Congress, and in fact only one party of them is so--the Moslem League, a reactionary conservative body composed of big landlords, title-holders and the like. Indeed, he adds, if a straight vote could be taken without confusing the issue by an appeal to communal fanaticism through such cries as "religion in danger", it is very doubtful if the Moslem League would have a majority over the combined votes of progressive Moslem parties. It was in fact decisively defeated in the last elections in the four provinces which have Moslem majorities. As for the Princes, they are, he says, a relic of feudalism, and do not represent their people. Although Mr. Amery's last offer, having regard to the conditions, was not so bad, it encouraged minorities to believe that however fantastic their claims, the British Government would support them, or at least allow them to hold up Home Rule indefinitely, thus lending colour to the Indian view that Britain does not really mean to give up her power and is playing the game of "divide and rule".

While it is desirable to place on record such a view of the facts of the situation in India in the interest of clearer understanding, it by no means must be held to imply assent among a people with whom religious belief and ritual is all-powerful as in India. The admission that successful opposition to the National Moslem League would depend upon the absence of an appeal to communal fanaticism, demands disruption of the social and religious functions of the individual member of a community in everyday life which is opposed to the whole of Indian culture and tradition. No doubt in many of the more progressive among the people of India, this tradition has become weaker, but nevertheless even among them it persists in some degree. It is for this among other reasons that competent observers have doubted the wisdom or even the possibility of applying the democratic ideal to Indian conditions. On this account, and not with the view of delaying Home Rule by fomenting intercommunal differences, the British Government has sought to accustom Indian ways of thought to respect for the rights of the individual through a compromise which, for the time being, appears to lay undue stress upon the claims of minorities. 